\title{
FACTS AND OBSERVATIONS
}

RESPECTING

\section{NTER M I TTENT FEVERS,}

AND THE

EXHALATIONS WHICH OCCASION THEM.

By Sir GILbERT BLANE, Bart. M.D. F.R.S. PUYSICIAN IN ORDINARY TO THE PRINCE REGENT.

Read March $3 d$, 1812.

Having been sent by the Government of this country on a special mission to the Island. of Walcheren, in the autumn of the year 1809, in order to ascertain the nature and causes of the great sickness and mortality prevailing in the British army in Zealand, and to make a report of my enquiries: having been also sent by the Admiralty to Northfleet, in the autumn of 1810 , in order to investigate the nature and situation of that spot in point of health, with a view to decide, whether any objection in point of unhealthfulness would arise to the formation of a projected dock-yard, and other naval establishments at that place, some observation's have occurred to me in executing these duties, which 
appeared to me sufficiently interesting to be laid before this Society.

During my residence in Walcheren, I not only visited all the hospitals, but inspected, with the permission of the Commander in Chief, the whole returns of the army from the time of their disembarkation, in order to ascertain the progress and extent of the sickness and mortality. The result of these enquiries is what I now propose to communicate, and, in describing the nature, and detailing the ravages of the prevailing disorder, I shall borrow the greater part of what $I$ have to say, from my official communications.

I arrived in the island on the 30th of September, and remained till the 13th of October following. During my stay I stated to the government, that I found so great a proportion of the sick to consist of those affected with the intermitting and remitting fevers peculiar to marshy countries, that there could be no doubt that the sickness of the army was owing to that cause.

The fever commonly called typhus, with which armies in ordinary circumstances are chiefly affected, had been rare, and dysentery, which, in the history of former campaigns * in the Low Countries, proved

* See Sir J.Pringle's Work on the diseases of the army, in which there is a most accurate history of the diseases prevailing in the British armies in Zealand and other parts of the Low Countries. 
so severe a scourge to our armies in the autumnal months, had been as yet but little felt. Both these diseases, however, had begun to shew themselves at Flushing, where the accommodations were at best far inferior to those at Middleburgh ; but were then still more so, in consequence of most of the buildings having been injured by the shot and shells thrown into the town during the siege. In the large and elegant city of Middleburgh, the accommodations were excellent, as we had not only the advantage of the hospitals formerly belonging to the Dutch and French troops, but the spacious and airy warehouses of the Dutch East India Company: this having been formerly the great emporium of Indian commerce. Here I found no typhus or dysentery, but the prevalence of these two diseases was very remarkable at Flushing, particularly in one regiment, of which all the medical officers were either absent or dead, and of which the sick originally affected with the endemic disease. were suffering also from typhus and dysentery, in consequence of the want of cleanliness, as well as of proper medicines, diet, and attendance. This fact affords a proof of the necessity of general hospitals on actual service, as well to prevent the generation and extension of infection, as to afford relief to the regimental establishments, when the sick and wounded accumulate beyond their means of accommodation. It is evident, in the present instance, how necessary this is even in stationary service; but with regard to the ordinary service of 
a campaign, where armies are in motion, and where regimental surgeons and their assistants must be present with the regiments, general hospitals may be regarded as absolutely indispensable. There ought also to be a liberal establishment of medical officers attached to such hospitals in case of emergencies of service, and to fill up such casual vacancies as may occur in regiments.

I found myself under the painful necessity, therefore, of stating, that the sickness on this island did not diminish. It appeared from the latest general weekly return, that there were two thirds of the whole numeral strength of the army incapable of duty. The mortality during the last four weeks had been about 1000. All the battalions were affected nearly in an equal degree; and it does not appear, that their illness was connected with the nature of their duty, or that it was owing to privations or neglect of any kind; for those were equally sickly, who had enjoyed the utmost ease and comfort in cantonments, as those who had been engaged in the siege of Flushing.

. Nor was this great sickness imputable to any thing unfavourable in the weather at this season, in comparison with former years. On the contrary, the native inhabitants affirmed, that they were then less sickly than usual at the same season of the year, and they accounted for this, from the uncommon quantity of rain that had fallen the last two months: 
consider it as fully established by observation, that the most sickly years are those, in which there had been great drought and heat in the latter end of summer and the early part of autumn; owing, probably, to the increased exhalation, and the more concentrated foulness of the stagnant water produced by these causes.

I found upon enquiry, that a like degree of sickness prevailed among the French troops who occupied Flushing during the last seven years; and that in former times, the Dutch troops, from the northern parts of the United Provinces, suffered equally. As the army had not suffered either from the scantiness and bad quality of provisions, nor from want of proper accommodation, nor from hardships and fatigue, it admits of no doubt, that the unfortunate state of the army here, was solely imputable to the contamination of the air from a soil the most productive of deleterious exhalations of any perhaps in Europe, producing anendemic fever which has at all times been particularly severe upon strangers in the autumnal months. I find also upon enquiry, that though this is by far the most sickly season, the residents of this and the neighbouring islands do not enjoy, at any season, the same degree of health, as the inhabitants of the more salubrious parts of Europe.

From this statement, it will be clearly perceived, how much the causes of sickness were out of the 
reach of human control. There were two facts, however, which afforded some encouragement for the employment of artificial means, in counteracting the overpowering influence of natural causes. One was, that those belonging to the upper orders of society in Walcheren were always less affected with its endemic fevers than the poorer inhabitants; the other, that the British officers suffered less in this campaign, than the private men, as will be seen by an abstract of the returns. As this latter must be owing to some circumstances of superior accommodation and diet, there was encouragement to attempt some improvement in these respects, though the situation of the common soldier was as comfortable as belongs to his condition. With this view I suggested the use of stoves in the barracks as well as the hospitals, in order to promote the dryness, warmth, and purity of the air. I also represented, that considerable benefit might arise from the men being supplied with a hot breakfast. It may likewise be remarked, that those who slept in the upper stories of houses, were less liable to the disease, and had it in a milder form, than those who slept on the ground floors. The testimony of the natives is in favor of this observation. We had a striking confirmation of it in the visit we paid to the party accommodated at Fort Rammekins. To the observation of General Monnet (the. French general who commanded during the siege) with respect to the good effect of a small quantity of ardent spirits in the morning, I may add a recom- 
mendation of mixing pepper freely with the broth and other articles of food.

There were in the beginning of October, when I arrived, considerably more than one half of the army sick, or convalescent in hospitals. This amount was not owing merely to the numbers accruing from those who were daily taken ill, but was swelled in consequence of the small number of discharges, and the numbers of convalescents waiting for a passage to England; for under the influence of the endemial air, recoveries were slow and imperfect, and relapses very frequent, not only among the few who were discharged, but among the convalescents at the hospital, some of whom, when apparently in a fair way of doing well, would unaccountably drop down dead. This made me urge the conveyance of such subjects to England, with as little delay as possible. There were then 6000 subjects proper for being transported to England; and I recommended, in conjunction with Dr. Macgregor, the superintendant of the military hospitals, that line of battle ships, with their lower deck guns taken out, should be sent from England for this purpose, there being at Walcheren only the means of conveyance for 1000 men. This measure was rendered further necessary, by the rapid accumulation of sick in the hospitals, some of which were already over-crowded, and, if not relieved, must in themselves have proved a source of additional sickness and infection. 
One of the most important circumstances in the operation of marsh miasma on the human body is the power of habit in mitigating its influence. The natives are not a robust people; they are of a very wan and sickly hue, and have all suffered more or less from the bad air which they breathe. The children of both sexes are very subject to glandular and abdominal complaints; and the adults, particularly those of the lower orders, have all of them, some time or other in the course of their lives, laboured under the endemic intermittent. They are, however, infinitely less subject to intermittent fevers than strangers. It was curious to remark, in conversing with the natives, even persons of education, and medical practitioners, that they would not admit their country to be more unhealthy than any other; and when they were asked to account for the great sickness prevailing among our troops, they mentioned some trivial circumstance in diet and habits of life, but would allow nothing to be ascribed to the insalubrity of the air. However unfounded this prejudice may be, it is strongly expressive of the great difference in point of health between natives and strangers. These strangers are also variously affected according to the district from which they come. It was found, that of the British troops, the natives of mountainous countries, and dry soils, were more frequently affected than the natives of flat and moist districts. It is also well ascertained, that strangers, if they survive the first attacks, become thereafter much less liable to the endemic intermittents. This was well 
proved and illustrated in a Mémoire which was discovered in the house of the French general Monnet. *

It was there recommended that troops should not be frequently changed; for when it was the custom to send battalions from Bergen op Zoom, every fourth night, in succession, to work on the lines of Flushing, these men never failed, on their return, to be taken ill in great numbers. General Monnet therefore advised, however displeasing it might be to officers, that a stationary garrison should be retained in Walcheren, in order that it might be habituated to the air, (acclimaté) and he instanced a French regiment, which suffered in the second year of its being stationed there only one half the sickness and mortality which it suffered the first year, and hardly suffered at all the third. There were some other important remarks in the Mémoire, such as, that when it might be necessary to reinforce the garrison, this should be done early in winter, in order that the men might be habituated to the climate before the return of the sickly months, which he reckoned to be June, July, August, and September. He also recommended, that men who mount guard, or who are employed in any other duty exposing them to cold damp or fatigue, should have a double ration of spirits (genievre,)

* General Monnet was an able man, and had commanded at Flushing during the whole seven years in which the French bad possession of that place. We may therefore admit the authority of his judgment and experience. 
and that there should be an additional allowance of this, and also of vinegar during the sickly months. Another remark of this general was very consolatory to us at this time, namely, that the oldest inhabitant did not remember a year, in which this endemic had not disappeared before the end of October.

The expedition to Zealand sailed from the Downs on the 28th of July, and made good their landing on Walcheren, and North and South Beveland, on the 31st of July and the 1st of August. The only military operation of consequence was the siege of Flushing, which was invested on the 1st of August, and capitulated on the 15th of the same month. In the beginning of September, the islands of North and South Beveland were evacuated, and that part of the army which occupied them, returned to England; about 18,000 being left to garrison Walcheren. More than one half of these died, or were sent to England on account of sickness in the course of the three following months; and the island was finally evacuated on the $23 \mathrm{~d}$ of December of that year.

The following tables exhibit a view of the course of the sickness and mortality. I was enabled to bring them down to the end of the campaign, the Commander in Chief having obligingly allowed me to extract from the returns deposited at the War Office, what was wanting in the notes which I had taken in Zealand. 
I am also enabled to state, on the authority of Dr. Bancroft*, and Mr. Keate the surgeon-general, that the whole number of sick sent to hospitals in Zealand, between the 21st of August and the 18th of November, 1809, amounted to 26,846 , including relapses, and that the number of sick, including a small number of wounded conveyed from thence to England, between the 21st of August and the 16th of December, amounted to 12,863 ; and that many instances occurred in those who returned to England apparently in health, in whom the endemial disease of Zealand appeared after the slight fatigue of a march.

Account of the Sickness and Mortality of the Army, in the Islands of. Zealand, abstracted from the Monthly Returns, 25th August, 1809, and the three subsequent Months.

HEAD QUARTERS, FORT BATHZ, SOUTH BEVELAND.

\begin{tabular}{|c|c|c|c|c|c|c|c|}
\hline \multirow[b]{2}{*}{$\begin{array}{l}\text { DATE } \\
\text { of the } \\
\text { Monthly } \\
\text { Return. }\end{array}$} & \multicolumn{2}{|c|}{ TOTAL. } & \multicolumn{3}{|c|}{ SICK. } & \multicolumn{2}{|c|}{ DIED. } \\
\hline & $\begin{array}{l}\text { Rank and } \\
\text { File and } \\
\text { Non-Com- } \\
\text { missioned } \\
\text { Officers. }\end{array}$ & $\begin{array}{c}\text { Com- } \\
\text { mis-: } \\
\text { sioned } \\
\text { Officers. }\end{array}$ & $\begin{array}{c}\text { In } \\
\text { Quar- } \\
\text { ters. }\end{array}$ & $\begin{array}{c}\text { In } \\
\text { Hos- } \\
\text { pi- } \\
\text { tals. }\end{array}$ & $\begin{array}{l}\text { To- } \\
\text { tal. }\end{array}$ & $\begin{array}{l}\text { Rank and } \\
\text { File and } \\
\text { Non-Com- } \\
\text { missioned } \\
\text { Officers. }\end{array}$ & $\begin{array}{l}\text { Offi- } \\
\text { cers. }\end{array}$ \\
\hline 5 Aug. & $416_{42}$ & I879 & 988 & 11713 & 2701 & +114 & If 7 \\
\hline
\end{tabular}

* Essay on the Yellow Fever, page 303 .

+ In this number 100 who were killed and died of wounds are included, so that only 14 died of disease.

$\ddagger$ Of these one was killed as above, and 6 died of wounds, so that none died of disease. 


\begin{tabular}{|c|c|c|c|c|c|c|c|}
\hline \multicolumn{8}{|c|}{ HEAD QUARTERS, } \\
\hline \multirow[b]{2}{*}{$\begin{array}{c}\text { DATE } \\
\text { of the } \\
\text { Monthly } \\
\text { Returns. }\end{array}$} & \multicolumn{2}{|c|}{ TOTAL. } & \multicolumn{3}{|c|}{ SICK. } & \multicolumn{2}{|c|}{ DIED. } \\
\hline & $\begin{array}{l}\text { Rank and } \\
\text { File and } \\
\text { Non-Com- } \\
\text { missioned } \\
\text { Officers. }\end{array}$ & $\begin{array}{c}\text { Com- } \\
\text { mis- } \\
\text { sioned } \\
\text { Officers. }\end{array}$ & $\begin{array}{c}\text { In } \\
\text { Quar- } \\
\text { ters. }\end{array}$ & $\mid \begin{array}{c}\text { In } \\
\text { Hos- } \\
\text { pi- } \\
\text { tals. }\end{array}$ & $\begin{array}{l}\text { To- } \\
\text { tal. }\end{array}$ & $\begin{array}{l}\text { Rank and } \\
\text { File and } \\
\text { Non-Com- } \\
\text { missioned } \\
\text { Officers. }\end{array}$ & $\begin{array}{l}\text { Offi- } \\
\text { cers. }\end{array}$ \\
\hline $\begin{array}{l}25 \text { Sep. I } 809 . \\
25 \text { Oct. } \\
25 \text { Nov. }\end{array}$ & $\begin{array}{r}16931 \\
\text { I I } 921 \\
6297 \\
\end{array}$ & $\begin{array}{l}723 \\
611 \\
452 \\
\end{array}$ & $\left|\begin{array}{r}3829 \\
2845 \\
469\end{array}\right|$ & $\mid \begin{array}{l}5000 \\
3027 \\
624\end{array}$ & $\left|\begin{array}{l}8829 \\
5872 \\
1093\end{array}\right|$ & $\begin{array}{l}883 \\
760 \\
196\end{array}$ & $\begin{array}{r}29 \\
9\end{array}$ \\
\hline
\end{tabular}

Account of the Sickness and Mortality in the Island of Walcheren, abstracted from the Weekly Returns, dated the 10th September, and the twelve subsequent Weeks.

\begin{tabular}{|c|c|c|c|c|c|c|}
\hline \multirow{2}{*}{$\begin{array}{c}\text { DATE } \\
\text { of the } \\
\text { Weekly Returns. }\end{array}$} & \multicolumn{3}{|c|}{$\begin{array}{c}\text { Rank and File } \\
\text { and } \\
\text { Non-Commissioned } \\
\text { Officers. }\end{array}$} & \multicolumn{3}{|c|}{ Officers. } \\
\hline & Total. & Sick. & Died. & Total. & Sick. & Died. \\
\hline $\begin{array}{l}\text { Io September } \\
\text { I } \\
24 \\
1 \\
8 \\
16 \\
16 \\
23 \\
31 \\
7 \text { November } \\
14 \\
21 \\
29 \\
\end{array}$ & $\begin{array}{l}17870 \\
17410 \\
16409 \\
16156 \\
15276 \\
13017 \\
11747 \\
8868 \\
7926 \\
6261 \\
\end{array}$ & $\begin{array}{l}6931 \\
8141 \\
8754 \\
9127 \\
8969 \\
7145 \\
6228 \\
3799 \\
1226 \\
1158 \\
\end{array}$ & \begin{tabular}{|c}
221 \\
277 \\
287 \\
254 \\
217 \\
Return \\
128 \\
121 \\
Return \\
40 \\
36 \\
30 \\
\end{tabular} & \begin{tabular}{|c|}
770 \\
765 \\
782 \\
748 \\
719 \\
mislaid \\
655 \\
292 \\
mislaid \\
559 \\
543 \\
$3^{83}$ \\
\end{tabular} & $\begin{array}{c}\text { No ret. } \\
235 \\
191 \\
172 \\
168 \\
113 \\
80\end{array}$ & $\begin{array}{l}4 \\
7 \\
3 \\
2 \\
3\end{array}$ \\
\hline
\end{tabular}

The first circumstance which strikes the eye on inspecting these tables, is the smallness of the mortality in the first month of servica It not only 
proves, that several weeks are necessary for these deleterious exhalations to act upon the system, so as to produce disease, but that the rate of this mortality is so much less than in ordinary circumstances, as to stagger one's belief. According to the statement here exhibited, only 14 died of disease in 41,462 in a calendar month, and not one officer. I at first distrusted my own accuracy in making the abstract; but repeated examination convinced me that I was correct. I next distrusted the accuracy of the returns, but the adjutant-general assured me that there was not the smallest reason to suspect an error. According to the population returns of 1801, the smallest degree of mortality in any of the counties of England and Wales, was in Pem. brokeshire; and was 1 in, 76. The greatest mortality was in London; and was 1 in 31 . But it is not fair to compare the mortality of an army, with that of the general population; for the latter includes all ages, sexes, and constitutions, whereas the former consists of the robust part of the male sex, in the prime of life. The computation being made on the like class, it would appear, that there is a much smaller rate of mortality than in people of the same age in London; for according to Simpson's tables*, the mortality here in men and women from 20 to 45 is at the rate of one in 42 annually; but the annual rate of it in this army, if computed by the month ending the 26th of August, would be only 1 in 247 .

* See Simpson's tables, London, 1752. 
This low rate of mortality will appear in a still more striking point of view, when compared with that of fleets and armies elsewhere: for at Coxheath in the year 1779*, the annual mortality was at the rate of 1 in 109; and during the time in which $I$ kept records of the fleet in the West Indies, the lowest in any month, April 1782, was equal to an annual mortality of 1 in 72 ; and the actual annual mortality about that time in the army was 1 in 4 , and in some particular spots more than one half.

Was this small rate of mortality in Zealand at this period, owing to the superior health and strength of those men who compose an army above the persons of both sexes, on whom the calculation is made in civil society? Or is it owing to this, that in the beginning of an expedition men's minds are in that elated state, from the sanguine hopes of victory and success, which is favorable to health? I have remarked elsewhere $t$, that in fleets, impressions of this kind have a striking effect on the health of men. Probably both the above-mentioned circumstances had a share in keeping down' the mortality at this period. This however was of short duration; for it will be seen by the Table, that the sick had begun to increase rapidly at this time; and that before the 10th of September, the mortality had become very great.. As there is no

* See Blane's Observations on the Diseases of Seamen, page I 70. Third Edition.

† Ibid. page 77 . 
account in these tables, of the numbers taken ill In the intermediate times, nor of those discharged cured; nor any accurate statement of the number sent to England from time to time, we have no scale of the decreasing sickness, as the season changed; except the weekly diminution of the number of effective men. Thus it will appear by a calculation made on table $2 \mathrm{~d}$, that in the week between the 17th and 24th of September, the effective force was reduced from 9269 to 7655 , so that 1 in 5.7 that is, about 2 in 11 , had in that time become unfit for duty. It will appear by a like calculation, that on the $23 \mathrm{~d}$ of October, the effective force was reduced to 5872 ; and that in the course of the succeeding week, it was reduced to 5519; so that 353 had in that time become unfit for duty, that is, 1 in 10.94, or about 1 in 11. By this rule, the sickness was diminished by one half in the course of a few weeks, making allowance for the greater number that will be taken ill at the beginning of a campaign : for the most susceptible will necessarily first fall ill. No fair judgment can be formed from the returns of November, for reinforcements, of the amount of which I am uninformed, arrived from England in the course of that month to assist in the evacuation of the island. From all the evidence however, I could procure, the number of seizures continued to diminish as the winter advanced, conformably to what we had been told by the natives. 
The island of Walcheren is 13 miles long from east to west, and 9 miles from north to south. The capital of this island and of all Zealand is Middleburgh, an open town in the centre of the island, but communicating with the sea by a broad and deep canal, continued from a natural navigable inlet, leading to Rammekens, on the south-east quarter of the island. Flushing on the south side of the island is the principal sea-port and arsenal, and the only place of strength. The whole island, with the exception of some hills, or rather mounds of sand on the western shore, is a dead flat, below the level of the sea at high water and preserved from inundation by dykes. The soil consists of a fine white sand, known in the eastern counties of England by the name of silt, and about a third part of clay. It is divided into small square inclosures, by ditches, which serve as drains ; and these were about two thirds full of turbid water when I was there. They emit no smell, that I could perceive; but I was sensible of a bad smell proceeding from some ponds of stagnating water. The soil seems to be a mass of alluvial matter like the deltas of great rivers; and the whole islands of Zealand seem to have been formed by the detritus carried down by the Rhine and Scheldt, and forming accumulations for a long series of ages. There is a poison in the exhalations from such soils, the nature of which is entirely unknown. It is not animal putrefaction; for it is perfectly well ascertained, that those who are exposed to putrid vapors, such 
as anatomists and tanners, are not affected by complaints of this kind; nor indeed by any complaint, unless these vapors are very concentrated; and the disease in that case is not an intermittent fever. Water in a state of stagnation, without any ascertainable principle of contamination, seems to generate these miasmata, particularly after it has undergone exhalation so as to be in the state of mud. It is only from the absence of stagnation, that we can account for the Delta of the Nile not producing the same disease as Zealand. This is so far from being the case, that Lower Egypt is one of the most healthful countries in the world, and is not infested with endemic intermittents. This remark did not escape the geographer Strabo *; and he assigns as the cause that the stagnation of the water was prevented by the annual inundation of the Nile. It appears also, from a work of Sir James Macgrigor, that intermittent fevers, though not unknown, are not endemic in Egypt $t$. On the other hand we know from the medical history of Minorcał, that, though this island consists of a rocky bottom, and very thin soil, yet in consequence of some stagnant water in channels and pools, severe intermittents are very common. I need hardly mention, that the plague is no exception, this being a disease

* Vid. Strabon. Geograph. lib. 17 . page 1143 . Amstelodam. 1707 .

† Vid. Medical Sketches of the Expedition to Egypt from India, by James Macgrigor, M.D., page 99 and $16_{3}$. London 1804.

$\ddagger$ Vid. Cleghorn on the Diseases of Minorca.

voL. III.

C 
depending on human effluvia, and entirely unconnected with the nature of the soil.

A very intelligent general officer* on the expedition to Egypt in the year 1800, who had served in all climates, assured me, that he had nowhere seen so little sickness and mortality from disease; for sickness, even including the plague, was less destructive than in any other country in which he had served; so that there was here an exception to a rule which holds every where else, that disease is more fatal than the sword; for the number of those who were killed, and died by wounds, was greater than that of those who perished by sickness, including even those who died of the plague. Nor can it be alleged, that humidity alone may have the effect of producing intermittent fevers : for the vapor of pure fresh water, when not in a state of long stagnation, is found to be free from any bad effects upon the greater number of constitutions. It is remarkable, that though much greater quantities of rain fall in the western parts of England than the eastern, the average in some counties of the former being more than double of what it is in those of the latter, yet it does not appear that health is in the least affected by this circumstance; and seamen, even in the thickest fogs on the banks of Newfoundland, for many days together, preserve their health perfectly. This poison, therefore, is some principle, with the nature of which we are

* The late Sir John Moore. 
still unacquainted, There are also certain species of decayed organic matter, the exhalations from which are not at all productive of agues nor any other disorder. I allude to bogs or peat mosses. This is fully proved in Scotland, but still more in Ireland, where there are immense tracts of this soil, without any hurtful influence upon health. It might naturally be expected also, that the swamps round Venice: would be productive of endemic fevers. This is not the case; and it is probably owing to the water which forms them, being sea-water.

The miasmata in Zealand, are more noxious than the like exhalations in England; the intermittents in the former, being more violent, untractable, and fatal, than those which occur in the fenny counties, in the eastern parts of our own country. I estimate this violence, by the high degree of febrile heat and delirium, by the excessive secretion of bile, the want of distinct intermissions, and the mare frequent swellings of the liver and spleen, these taking place in the course of a very few weeks, which in England seldom occur but under a long continuance, or from frequent relapses of the disease.

The exhalations of the soil in tropical climates; extend farther, and are still more malignant than those of Zealand. Ships at the distance of $\mathbf{3 0 0 0}$ feet from swampy shores, (a distance to which it did not extend in Zealand,) and even farther, were affected by the noxious exhalations, according to 
my own observations and those of others in the West Indies; and I have been credibly informed of the like fact, with regard to the India ships in the channel which leads to Calcutta. This greater density and malignity of the exhalations, might naturally be expected from the greater intensity of atmospheric heat.

A medical gentleman belonging to the army in St. Lucia, one of the Caribbee Islands, in the year 1781, at which time I was Physician to the fleet on that station, favored me with the following statement, which throws considerable light on the subject here treated of.

"The Fevers in general are of the low kind, ter" minating in intermittents.

" Unhealthy situations are the causes of many " diseases here, particularly the worst sort of fever " and intermittents.

"One regiment, viz. the 90th on the Morne " Fortunée, lost $271 \mathrm{men}$; the 91st on the side of " the hill, 318; the 89th in Grand Cul de Sac at the “6 bottom, 486.

"The hill or morne is above the level of the sea “s 872 feet." 
ON THE WALCHEREN FEVER.

\begin{tabular}{|c|c|c|c|}
\hline \multicolumn{2}{|c|}{ 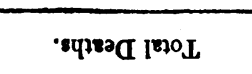 } & 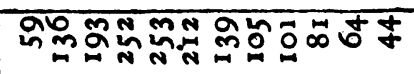 & के \\
\hline \multicolumn{2}{|c|}{$\cdot x+5$ [870] } & ఫষ் జ & ఫేّ \\
\hline \multicolumn{2}{|c|}{ 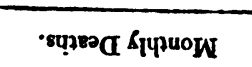 } & 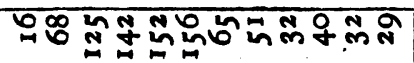 & $\infty$ \\
\hline \multicolumn{2}{|c|}{ 'PJ!S jo daqunn } & 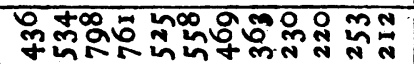 & 7 \\
\hline \multicolumn{2}{|c|}{ 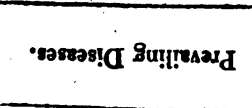 } & 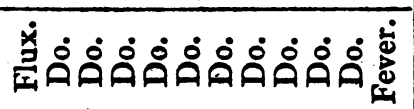 & 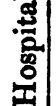 \\
\hline \multirow{4}{*}{ 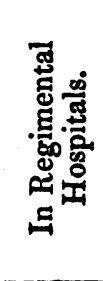 } & -Sedos $\mathbb{a}$ & 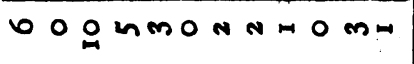 & \multirow{4}{*}{ 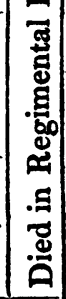 } \\
\hline & $\cdot \cos n$ IJI & 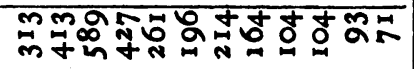 & \\
\hline & $\cdot \operatorname{son} 9 \dot{y}$ & 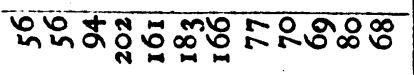 & \\
\hline & 'sגәАәд & 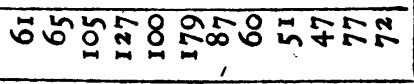 & \\
\hline \multicolumn{2}{|c|}{ 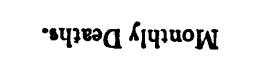 } & 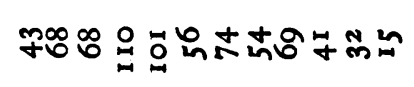 & $m$ \\
\hline \multicolumn{2}{|c|}{ •Pग!S jo doqunn } & 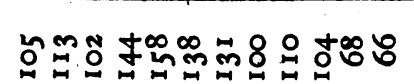 & \multirow{6}{*}{ 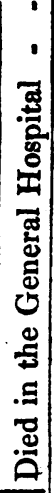 } \\
\hline •saseas! & a!!!Baอd $\mathbf{d}$ & 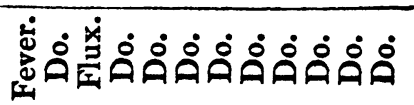 & \\
\hline \multirow{4}{*}{ 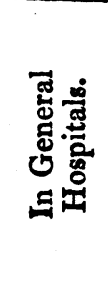 } & $\cdot$ - isdox $\alpha$ & $m+m \infty m+n \rightarrow m m o$ & \\
\hline & $\cdot \operatorname{sexn} 1 d$ & 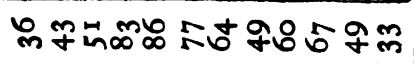 & \\
\hline & $\cdot \operatorname{san} 8 \mathrm{~V}$ & 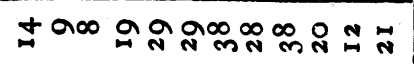 & \\
\hline & 'SدOAOJ & 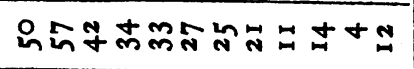 & \\
\hline \multicolumn{2}{|c|}{ 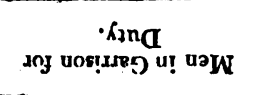 } & \multicolumn{2}{|l|}{ か } \\
\hline \multicolumn{2}{|c|}{ 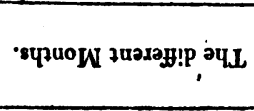 } & 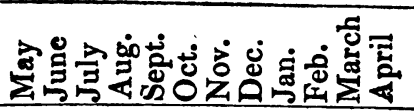 & \\
\hline \multicolumn{2}{|c|}{ 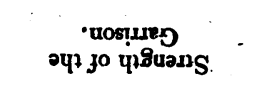 } & ผN丶m & \\
\hline
\end{tabular}


It is evident that the severity of the symptoms, in the Zealand fever, added greatly to the difficulty of the cure; and there could be no opportunity of employing Peruvian Bark or other specific remedies, till its violence had abated, and the redundant bile had been carried off. The treatment of this acute state, consisted chiefly in giving such remedies as purged freely; and in selecting them, the preference was due to those which acted most readily on the liver and the bile, as calomel; those which were least heating, as the neutral salts ; and such as were best borne by the stomach, which, in a great many cases, was extremely irritable, as the carbonate of magnesia in effervescence with lemon-juice. In the course of the general inspection, in which my duty consisted at this time, I had not myself an opportunity of directing and watching the practical details of individual cases; but I had considerable experience in this way, in my attendance on offcers in England, who either brought the complaint with them, or were seized on the passage, or after their return to this country.

One of the medical controversies respecting the cause of intermittents, is founded on the difference of opinion on the question, how far the excess of bile may be considered as the cause of them. It certainly cannot, in correct language, be called the cause; otherwise every case of redundant bile, such as the cholera morbus, would be attended or followed by an ague. Certain it is, however, that 
epidemic intermittents not only occur exclusively in those seasons in which an excessive secretion of bile is most apt to arise, but every attack, whether original or relapsed, which I have seen, bore evident marks of an excessive flow of this humor. The true statement of the fact perhaps is, that that state of the body, in which there is the strongest tendency to a copious secretion of bile, either from the natural constitution, or the season of the year, constitutes a predisposition favourable to the action of the poisonous exhalations. There seems in this something analogous to other facts mentioned in a former paper respecting the Plague and the Yellow Fever, namely, that the human body is not liable to be affected by them, unless when predisposed by a certain temperature of the atmosphere. If the attack of this disease depended merely on the quantity of the exhalations, they would be most frequent in June and July, when the heat of the atmosphere is highest. But there is a still more decisive proof of its depending on that season, in which the secretion of bile is most copious, from this fact, that when those who have imbibed the poison, are transported into countries where the air is in a state of greatest purity, it is in the autumnal months, that they are most commonly attacked. There was a very striking proof of this after the campaign of North Holland in 1799. In the following year some of the officers and men who had escaped the disease, were taken ill in the autumnal months; and none that I heard of, at any other season of the year. 
The greatest difficulties which occurred in the cure of those severe intermittents in their early stages, proceeded from the great irritability of stomach, which rendered it very difficult to exhibit either purgatives with a view to procure intermissions, or bark in sufficient quantity after intermissions had been procured. The best means, I found, of obviating the first difficulty, was to purge with calomel, which, besides the advantage already mentioned, is, on account of its small bulk, swallowed without repugnance, and, by its weight, is not easily rejected after being swallowed; and in case the stomach rejected neutral salts, to assist its operation by considerable quantities of carbonated magnesia given in effervescence with lemon-juice. It is sometimes, though very rarely, advisable to give mercury as an alterative. Ramazini * relates, that a person affected with an obstinate ague was cured by mercurial friction administered for the lues venerea. The second difficulty was obviated by substituting opium and arsenic for bark. The stomachs of some patients were reconciled to the bark, by administering it with opium or magnesia in effervescence, or both; to others it was so insuperably offensive, that it could not be borne in any form, quantity, or combination. In these cases, the cure was effected by opium and arsenic, along with such bitters and aromatics, as the stomach would bear. Where the periodical paroxysms had not ceased, the tincture of opium was given from 30 to $50 \mathrm{drops}_{2}$ in

* De morbis artificum. 
the intermission, a few hours before the expected hour of seizure, accompanied with as much rhubarb as would counteract its restringent effects. Sometimes the first administration of this stopped the paroxysm; but more commonly only alleviated it, and did not stop it till the second or third time*. After the paroxysms were stopped, it was continued in smaller doses at the former periods; and either bark, or, if the stomach would not bear it, arsenic + was given in the intervals, till it might reasonably be supposed that the tendency to relapse had ceased. At this period, carbonate of iron was also given with safety and advantage, and with still more benefit at a more advanced period, in order to obviate debility and emaciation, and to afford a still greater security against relapse, when there were no remains of fever, nor suspicion of local affection. I have cured intermittent fevers in which bark had failed both in the West Indies $\ddagger$, and in St. Thomas's Hospital, with the oxide of zinc; but $I$ have made little use of this remedy since I became acquainted with the superior powers of opium and arsenic.

* I read in the Surgeon's journal of a man of war, that a drachm of ether given an hour before the period of an intermittent, stopped the paroxysm. Though this is a medicine, probably not sufficiently potent as a general and exclusive remedy, it would be a good addition to the liquid vehicle in which other medicines are exhibited.

+ The dose was from six to twelve drops of the liquor arsenicalis of the London Pharmacopeia, three times a day.

$\$$ See Observations on the Diseases of Seamen, page 442. Third Edition. 
The duration of this tendency to relapse, was very indefinite. There is a subtle, incomprehensible impression made on the living human body by marshy exhalations, which, though attended with no immediate visible effect, so modify the constitution, that many months afterwards, though the person has been living all the while in a pure air, an intermittent fever arises sometimes, without any visible exciting cause; but most frequently in consequence of cold, fatigue, watching, privation of some kind, or, as has been before mentioned, on the return of the autumn. This, as has been already remarked, was strikingly exemplified in the troops who had served in the campaign in North Holland, in September and October, 1799. Among these, was an officer who came to town to put himself under my care in the month of August in the following year. He belonged to an encampment at Swinly near Windsor, a district not liable to such complaints; and he informed me, that not only himself, but others who had not been affected in Holland, had been seized with intermittents, and that this disorder was confined to those who had been in the abovementioned campaign. I was informed in February, 1811, by a field officer, who came home from Portugal on account of bad health, that those men of his own regiment as well as of others, who had served before in Walcheren, were, upon the first exposure and fatigue, rendered unfit for duty, chiefly by remittent fevers, so as to leave not more than a third part of them fit for service. Here there was a 
proportion of sick, far above that of the army in general. This tendency is still stronger, if the person had actually suffered from immediate exposure to these exhalations; a consideration which obviously suggests the necessity of continuing the remedies for a considerable time after.all the symptoms of the complaint have subsided, and also of avoiding the exciting causes above enumerated.

I Lad, in the course of this service, an opportunity of obsierving the extent to which the noxious exhalationsi extended, which was found to be less than is, I believe, generally known. Not only the crews of the ships in the road of Flushing, were entirely free from this endemic; but also the guardships which wore stationed in the narrow channel between this islan $t$ and Beveland. The width of this channel is about $6000 \mathrm{feet}$; yet, thaugh some of the ships lay much nearer to one shore, than to the other, there was no instance of any of the men or officers being taken ill with the same disorder, as that with which the troops on shore were affected.

1 had an opportunity of farther proving and illustrating this observation, in the service I was sent upon to Northfleet in the autumn of the following year. The spot upon which it is intended to erect the proposed dock-yard and arsenal, is a marsh of about 700 acres. On the banks of the river, both above and below it, there is a soil of a similar description, but not immediately adjoining 
to it on either side; for above is the village of Green Hithe, which stands on a chalky bottom, rising to a few inches below the surface, and is a projecting point of the general chalky hills which compose the adjacent country.- Below it, on te bank of the river, there is a similar interventibn of the chalk, where the village of Northteet stands. Both these are nearly on a level with the marsh; yet the intermittent fevers are al nost unknown at either of them, whereas they are extremely prevalent on the adjacent hills. I found this fact analogous to some others to which my enquiries at this time led me. Dr. Maton informed me, that in the neighbourhood of Weymouth, though there is stagnating water near the sea, producing intermittents, these disorders are nc,t known in the dry districts on each side, on a level with the water, but prevail on the adjacent hills. A Cornish gentleman stated to me, that at St. Blazey, between St. Austle and Lestwithiel, agues prevail much on a hill adjoining to a marsh contiguous to the sea beach. And Major Rennel, the celebrated geographer, says, that in a district which he surveyed on the river Burrampooter, the waters of which overflow, and, upon retiring, leave an oozy flat, the agues prevail to the very summit of the adjoining hills. Lancisi mentions a hill, on which the same sickness prevails, as in the marshy lands at the foot of it*. An instance of the same fact in St. Lueia, has been already mentioned.

* Vid. Lancisi de Noxiis Paludum Efluviis, page 120, Roma. I717. 
It is known to every one, ever so little acquainted with the operations of nature, and indeed the common phenomena of clouds and rain render it obvious to the most ordinary observer, that water, recently exhaled from the surface of the earth, has a tendency to ascend, and being lifted over parts on the same level, impinges on the neighbouring heights. There is reason to believe that impure and unwholesome particles in general are attracted by watery vapors, for it is remarkable, that, in case of fogs, offensive smells are perceived, which in a dry state of the air were fixed and quiescent. Though pure humidity, therefore, is innocuous. it may prove pernicious as a vehicle of unwholesome volatile matter. In like manner, the poisonous principle of marshes, whatever it is, being engendered by moist soils, will naturally adhere to the watery vapors, and ascend with them.

There are facts to prove, that certain artificial changes tend greatly to improve the air of particular spots. It is well ascertained, by the records of physic, by the bills of mortality, and by civil history*, that intermittent fevers were very prevalent in London, before the formation of common sewers and the adoption of other means, such as paving, conducive to cleanliness and dryness, to which, more perhaps than to the improved habits of life, in point of diet, may be ascribed the unexampled

* King James the First, and Oliver Cromwell, both died of agues contracted in London. 
state of health in this great metropolis. There is a still stronger proof and illustration of this in Portsmouth, which is built upon a flat, composing part of the marshy island of Portsea. I am assured by a medical gentleman who practised there, but is now retired from practice, that when he first knew that place, intermittent fevers were very pre. valent; but the town having been drained and paved in the year 1769, that disorder has since been unknown there*. Hilsea and other parts of the Island of Portsea have retained the same aguish character; but this disease has greatly decreased there also, since a drainage which was made in the year 1793. Numberless other examples might be adduced in proof of this, derived from the general improved state of health in various parts of the kingdom, in consequence of the inclosure of commons for the purpose of agricultural improvements of which draining is one of the principal. This has been felt on the spot now in question, for I am assured by the Rev. Mr. Crackhilt, who has resided in the parish of Northfleet for 12 years, that there has been

* It appears from the late Parliamentary Report, that Portsmouth has had an accession to its population, during the last ten years, of 840 r inhabitants; that the healthfulness of it has encreased, the proportion of deaths in 1800 having been one in 28 ; in 1810 , one in 35 ; both computations being taken on an arerage of three years. Plymouth in the same time has acquired an additional population of 12,866 , and the mortality has varied but little, having been one in 27 in 1800 , and not quite one in 28 in 1810. The population of Portsmouth, by the last Report, was 40,567; that of Plymouth, 56,060. 
in that time a progressive amelioration in point of health.

It is mentioned by Bishop Burnet, in his History of the Reformation, that in the last year of Queen Mary's rẹign, "Intermitting fevers were so universal and contagious, that they raged like a plague ;" and we learn from Sydenham and Morton, that intermittent fever was one of the most prevalent and fatal disorders in London from 1661 till 1665, and that for some years afterwards this complaint was very rare. This was probably owing to the greater dryness of the streets by draining, when the city was rebuilt after the great fire of 1666 . We are told however by Sydenham, that intermittent fevers revived before the end of that century, and were epidemic from 1677 to 1685 . They prevailed a good deal during the first part of the 18th century; and we learn from a work of Dr. Fothergill's, that they occurred as an annual epidemic in the spring and autumn, as late as the years 1751, 1753 and 1754. For more than 30 years past, according to my own observation and the best information I can gather from others, this disease has not been known as an epidemic in this metropolis. I was physician to St. Thomas's Hospital, from the year 1783 till 1795, during which period, the whole number of intermittents that fell under my care, was 192. As there were three physicians, this may be reckoned the third part of the whole admissions for ten years in an hospital containing on an average about $\mathbf{4 3 0}$ 
patients. I have not noted in my journal, from what quarter they came; but my memory perfectly warrants me in affirming, that the great majority of them were labourers from marshy districts, particularly Kent and Essex, and there is this internal proof of the greater part being strangers, that, of the number above specified, only 33 were females. Had they belonged to the resident population, the number of each sex would have been nearly equal. On referring to the notes, which I keep of my private practice, I find that in the course of 25 years, I have met with 63 intermittents. Of these, 12 belonged to the armies, that had served in Holland or Zealand, and of the number affected in England, more than one half came from the aguish counties. Several of the cases of those who belonged to the resident population, were so slight and irregular, as to render it doubtful whether they were strictly referable to this genus of disease.

One of the objects prescribed to me on my visit to Northfleet, was to ascertain how far the health of that spot might be affected by the exhalations from the Essex side of the river. What has been already said on the subject relating to Zealand, affords an answer to this question; the width of the channel between Walcheren and Beveland being about six thousand feet, and the breadth of the river at Northfleet, according to a plan in the possession of Mr. Rennie the engineer, being three thousand feet. The distance of Essex from the 
bank of the river at Northfleet, is therefore about the same as between the ships riding in the middle of the channel, between the shores of Walcheren and Beveland. I found, however, from the most accurate enquiry, that the endemic fever had not spread, either to the ships of war in the roads of Flushing, or to those stationed between the islands, though some of them were nearer the shore than the middle of the channel.

I was further informed by Mr. Rennie, that in boring the ground at Northfleet, he found that there were beds of ehalk and gravel underneath the clay, so that these materials, when thrown up in making the excavations, would render the surface dry and wholesome; and that he had calculated their quantity would be such, as to raise the artificial surface eighteen feet higher than the present natural surface.

Taking into consideration, therefore, the great changes which would take place in the marshy spot on which it was proposed to erect the docks and arsenals, in consequence of the excavations, the drainings, the pavings, buildings, and various other operations for forges and other machinery, I gave it as my opinion, that no solid objection, on the score of health, would arise to the plan proposed. 